On reconstruction of time series in climatology

\title{
On reconstruction of time series in climatology
}

\section{Privalsky ${ }^{1}$ and A. Gluhovsky ${ }^{2}$}

${ }^{1}$ Space Dynamics Laboratory (ret.), VEP Consulting, Logan, Utah, USA

${ }^{2}$ Department of Earth, Atmospheric, and Planetary Sciences and Department of Statistics, Purdue University, West Lafayette, Indiana, USA

Received: 28 July 2015 - Accepted: 1 September 2015 - Published: 6 October 2015 Correspondence to: V. Privalsky (vprivalsky@gmail.com)

Published by Copernicus Publications on behalf of the European Geosciences Union.

Title Page

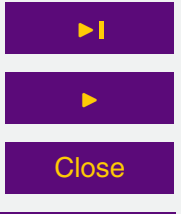

Full Screen / Esc

Printer-friendly Version

Interactive Discussion 


\section{Abstract}

The approach to time series reconstruction in climatology based upon cross-correlation coefficients and regression equations is mathematically incorrect because it ignores the dependence of time series upon their past. The proper method described here for 5 the bivariate case requires the autoregressive time- and frequency domains modeling of the time series which contains simultaneous observations of both scalar series with subsequent application of the model to restore the shorter one into the past. The method presents further development of previous efforts taken by a number of authors starting from A. Douglass who introduced some concepts of time series analysis into climatology. The method is applied to the monthly data of total solar irradiance (TSI), 1979-2014, and sunspot numbers (SSN), 1749-2014, to restore the TSI data over 1749-1978. The results of the reconstruction are in statistical agreement with observations.

\section{Introduction}

15 An important task in climatology and paleoclimatology consists in the reconstruction of a time series of some variable over the time interval when that variable was not measured. This task is solved by using proxy data - observations of a different variable, or variables supposed to be closely related to the variable of interest during the time interval of interest. A typical example would be restoring the annual surface temperature over the past centuries using dendrochronology data - time series of annual tree ring widths within the geographical area of interest. The observation data over the time interval when both variables (tree rings as the proxy and temperature as the variable to be restored) have been properly measured, are analysed and the relation between them is used to reconstruct the temperature time series into a more or less distant past, depending on the amount of tree rings observations. Quite often, the mathematical tool applied for this purpose is the linear regression analysis. If the estimate of

\section{CPD}

11, 4701-4728, 2015
On reconstruction of time series in climatology
V. Privalsky and A. Gluhovsky

\section{Title Page}

Abstract Introduction Conclusions References Tables Figures

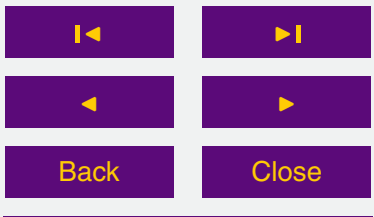
Full Screen / Esc

Printer-friendly Version

Interactive Discussion 
the cross-correlation coefficient between the time series of the proxy variable and the variable that is being reconstructed on the basis of the available simultaneous observations is high, a regression equation is built and the missing past values of temperature are reconstructed on the basis of that equation. This is how it is done both in the sim5 plest bivariate case (a proxy and the variable to be restored) and in the multivariate case when the variable of interest is reconstructed on the basis of a multivariate linear regression equation (e.g., Bradley, 2015; Santos et al., 2015). The variables can be transformed in some way before the reconstruction (for example, time series of principal components of expansions into empirical orthogonal functions are used instead of 10 the original data, see Tingley et al., 2012) but the general principle remains the same: build a regression equation.

Yet, this cross-correlation/regression approach is generally not correct for analysing multivariate time series. Their statistical properties cannot be understood and the missing past data should not be reconstructed without a more sophisticated analysis than 15 just through cross-correlation coefficients and regression equations. The key factor that makes time series behave in a more complicated manner is their dependence upon time and, consequently, upon frequency, which does not exist in the case of random variables for which a cross-correlation coefficient and a regression equation are exhaustive. Generally, consecutive values of time series depend upon their past and the relationship between the scalar components of a multivariate time series depends upon past values of all of its components. The time domain properties define the time series' properties in the frequency domain, and their study allows one to obtain additional information about relations between the scalar components of a multivariate time series.

The goals of this study are to show how to

- analyze a multivariate time series in time and frequency domains to obtain and interpret the information necessary for reconstructing one of the time series' components into the past and

\section{CPD}

$11,4701-4728,2015$

On reconstruction of time series in climatology

V. Privalsky and A. Gluhovsky

Title Page

Abstract

Conclusions References

Tables

Figures

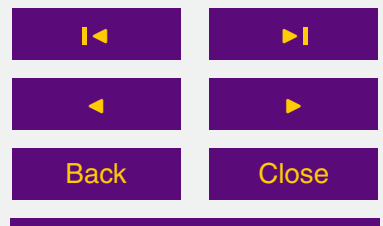

Full Screen / Esc

Printer-friendly Version

Interactive Discussion 
- apply the results of this analysis to reconstruct past values of the time series on the basis of observations made during a relatively short and recent time interval.

Section 2 contains some historical notes, Sect. 3 describes the mathematical approach used in the paper; it is based upon autoregressive time- and frequency domains analysis of multivariate (in our case, bivariate) time series. Section 4 provides an example with actual bivariate data (the data description and steps to be taken to reconstruct the time series). The methodology and results are summed up in Sect. 5, which also contains some practical recommendations.

\section{Historical notes}

Seemingly the first effort to reconstruct a climatic time series was made by the founder of the science of dendrochronology A. Douglass who suggested "a mathematical formula for calculating the growth of trees when the rainfall is known" and vice versa (Douglass, 1919). His studies of tree rings growth and climate dependence upon each other and upon sunspot numbers include important achievements such as

- discovering and analyzing dependence between time series of tree-rings growth and sunspot numbers (Douglass, 1909, p. 228; Douglass, 1928),

- suggesting an extended memory (autoregressive) type of model for the time series of precipitation (1919, p. 68),

- regarding the sunspot - tree rings system as inertial (Douglass, 1936),

- noting that the correlation coefficient may not properly reflect the dependence between time series ("The similarity between two trees curves ... is only partly expressed by a correlation coefficient." Douglass, 1936, p. 29),

- studying time series in the frequency domain by using the Schuster periodogram (Douglass, 1919, pp. 86-110).

\section{CPD}

$11,4701-4728,2015$

On reconstruction of time series in climatology

V. Privalsky and A. Gluhovsky

Title Page

Abstract Introduction Conclusions References Tables Figures

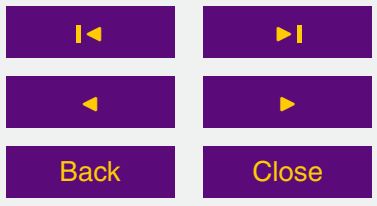

Full Screen / Esc

Printer-friendly Version

Interactive Discussion 
The first analyses that take into account the behavior of time series of climate and tree-rings in both time and frequency domains through correlation functions, spectra, and coherence functions and describe the response of tree-growths to climatic factors were conducted by Fritts (1976). Concepts of response functions "to describe the tree5 ring response to variation in climate" and transfer function, "which transforms values of ring width into estimates of climate...", were also introduced, adverse effects of filtering noted but no explicit time- or frequency domains models was suggested. A frequency domain description of tree-ring and climate data through coherence function estimates was also given by Guiot (1982).

10 Probably, the first example of building an explicit time-domain model was presented by Guiot (1985) who used a set of "mutually exclusive" linear filters to split the entire frequency range of the data into separate frequency bands, obtained a regression equation for each band and then combined them into a single time-domain equation connecting temperature to tree-rings.

15 Guiot (1986) introduced the concept of parametric time domain models into paleoclimatology and used scalar ARMA models and/or regression equation to estimate the transfer function. The reconstruction quality was estimated on the basis of correlation coefficients with an "optimal" proxy data set.

More efforts were undertaken later to apply methods of time series analysis in pale20 oclimatology, including the use of the Kalman filter (Visser and Molenaar, 1988) as well as applications of the Bayesian approach to climate reconstruction (e.g., von Storch et al., 2004; Hasslett et al., 2006; Tingley and Hubert, 2010).

Though the correlation/regression approach still seems to prevail in paleoclimatology, our approach based upon an explicit time-domain model of the tree-rings-climate system in the form of a bivariate stochastic difference equation including system's description in the frequency domain should be regarded as an improvement of methods suggested by previous authors starting from the founder of dendrochronology A. Douglass.

\section{CPD}

11, 4701-4728, 2015

On reconstruction of time series in climatology

V. Privalsky and A. Gluhovsky

Title Page

Abstract

Conclusions References

Tables

Figures

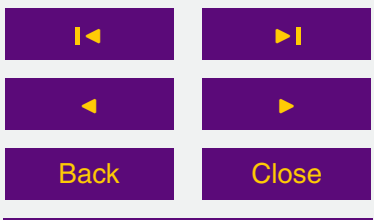

Full Screen / Esc

Printer-friendly Version

Interactive Discussion 


\section{Data analysis tools}

The basic difference between random variables and random functions had been revealed almost 60 years ago in the classical work by Gelfand and Yaglom (1957). They proved, in particular, that the amount of information about a (Gaussian) random vari5 able $x_{1}$ contained in another (Gaussian) random variable $x_{2}$ is $J=-\frac{1}{2} \log \left(1-r_{12}^{2}\right)$, where $r_{12}$ is the correlation coefficient between the variables. According to their fundamental results, the respective information quantity - the average information rate per unit time - for discrete stationary random functions $x_{1, n}$ and $x_{2, n}$ is

$i\left(x_{1, n}, x_{2, n}\right)=\int_{0}^{f_{N}} \log \left[1-\gamma_{12}^{2}(f)\right] \mathrm{d} f$

10 where $\gamma_{12}^{2}(f)$ is the coherence squared function (see below), $f$ is the frequency, $f_{N}=1 / 2 \Delta t$ is the Nyquist frequency, and $\Delta t$ is the sampling interval. Thus, the dependence between time series is described with a function of frequency and is not associated with the cross-correlation coefficient. In other words, the cross-correlation coefficient cannot characterize relations between the components of a multivariate time 15 series. The coherence function was used in paleoclimatology by Fritts (1976) and other authors (see Sect. 2) at the time when the time series analysis has already become a well-developed science but the Douglass' remark regarding the inadequacy of the correlation coefficient for time series analysis made as early as in 1936 looks quite visionary.

$20 \quad$ Monographs and papers on methods of multiple time series analysis including estimation of the coherence function started to appear in the 1960's and are well-known in random processes (Bendat and Piersol, 1966), in geophysics (Robinson, 1967), and in econometrics (Granger and Hatanaka, 1964; Granger, 1969). None of those methods relies upon cross-correlation coefficients and regression equations.

\section{CPD}

11, 4701-4728, 2015

On reconstruction of time series in climatology

V. Privalsky and A. Gluhovsky

Title Page

Abstract

Conclusions

Tables

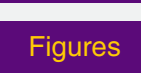

14

4

Back

Introduction

References Figures

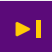

$>$

Close

Full Screen / Esc

Printer-friendly Version

Interactive Discussion 


\section{CPD}

$11,4701-4728,2015$

where $x_{1}, x_{2}$, and a are zero mean random variables, should change in the case of a bivariate zero mean time series $\mathbf{x}_{n}=\left[x_{1, n}, x_{2, n}\right]^{\prime}$ (the strike denotes matrix transposition).

5 For the time series $\mathbf{x}_{n}, n=1,2, \ldots$, one should expect that its scalar components $x_{1, n}$ and $x_{2, n}$ depend upon their own past values and, possibly, upon the past values of the other component. This means that the linear regression Eq. (1) would be transformed into a system of linear stochastic difference equations

$x_{1, n}=\varphi_{11}^{(1)} x_{1, n-1}+\varphi_{12}^{(1)} x_{2, n-1}+\ldots+\varphi_{11}^{(p)} x_{1, n-p}+\varphi_{12}^{(p)} x_{2, n-p}+a_{1, n}$

$10 \quad x_{2, n}=\varphi_{21}^{(1)} x_{1, n-1}+\varphi_{22}^{(1)} x_{2, n-1}+\ldots+\varphi_{21}^{(p)} x_{1, n-p}+\varphi_{22}^{(p)} x_{2, n-p}+a_{2, n}$.

which presents a generalization of the regression Eq. (1) to the case of bivariate time series. Here $a_{1, n}$ and $a_{2, n}$ are white noise innovation sequences (time series analogs of the regression error $a$ in Eq. 1), the coefficients $\varphi_{11}^{(i)}, \varphi_{22}^{(i)}, i=1, \ldots, p$ define the dependence of $x_{1, n}$ and $x_{2, n}$ upon their own past values, $\varphi_{12}^{(i)}, \varphi_{21}^{(i)}, i=1, \ldots, p$ describe the connection between $x_{1, n}$ and $x_{2, n}$, and the integer parameter $p$ is the largest time lag, at which any of the coefficients $\varphi_{i j}^{(i)}$ in Eq. (2) is statistically different from zero.

In a matrix form, Eq. (2) is written as

$\mathbf{x}_{n}=\sum_{j=1}^{p} \boldsymbol{\Phi}_{j} \mathbf{x}_{n-j}+\mathbf{a}_{n}$,

where

$\boldsymbol{\Phi}_{j}=\left[\begin{array}{ll}\varphi_{11}^{(j)} & \varphi_{12}^{(j)} \\ \varphi_{21}^{(j)} & \varphi_{22}^{(j)}\end{array}\right]$
On reconstruction of time series in climatology

V. Privalsky and
A. Gluhovsky

Title Page

Abstract

Introduction

Conclusions References

Tables

Figures

14

$\rightarrow 1$

4

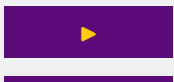

Back

Close

Full Screen / Esc

Printer-friendly Version

Interactive Discussion 
and $\mathbf{a}_{n}=\left[a_{1, n}, a_{2, n}\right]^{\prime}$.

The stochastic difference Eq. (2) (or its matrix form Eq. 3) is a bivariate autoregressive model of order $p$ [notation: $\mathrm{AR}(p)$ ] and its innovation sequence covariance matrix is

${ }_{5} \quad \mathbf{R}_{\mathrm{a}}=\left[\begin{array}{ll}R_{11} & R_{12} \\ R_{21} & R_{22}\end{array}\right]$.

It is important to note that the AR model has appeared here not because it had been used in the classical monograph by Box and Jenkins (1970) or anywhere else but because it followed directly from the desire to properly describe the linear connection between two scalar time series.

10 The properties of the time series $\mathbf{x}_{n}$ in the frequency domain are described with the spectral matrix

$\mathbf{s}(f)=\left[\begin{array}{ll}s_{11}(f) & s_{12}(f) \\ s_{21}(f) & s_{22}(f)\end{array}\right]$,

which is obtained through a Fourier transform of Eq. (3). Here, $s_{11}(f), s_{22}(f)$ are the spectra and $s_{12}(f), s_{21}(f)$ are the complex-conjugated cross-spectra of the time series $15 \quad x_{1, n}$ and $x_{2, n}$.

In particular, the coherence squared function is found from the matrix Eq. (6) as

$\gamma_{12}^{2}(f)=\frac{\left|s_{12}(f)\right|^{2}}{s_{11}(f) s_{22}(f)}$

(e.g., Bendat and Piersol, 2010).

The coherence function $\gamma_{12}(f)$, which satisfies the condition $0 \leq \gamma_{12}(f) \leq 1$, can be 20 regarded as a frequency-dependent "cross-correlation coefficient" between the components of a bivariate time series. In order to stress the similarity between the coherence function and the cross-correlation coefficient, we will be using $\gamma_{12}(f)$ rather than the coherence squared Eq. (7). But it is the coherence function and not the cross-correlation
CPD

$11,4701-4728,2015$

On reconstruction of time series in climatology

V. Privalsky and

A. Gluhovsky

Title Page

Abstract Introduction

Conclusions References

Tables

Figures

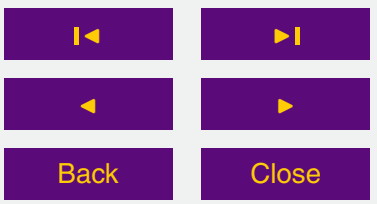

Full Screen / Esc

Printer-friendly Version

Interactive Discussion 
coefficient that defines the degree of linear dependence between the components of a bivarite time series.

Other functions of frequency that describe relations between time series, such as coherent spectra and frequency response functions (e.g., Bendat and Piersol, 2010), 5 will not be used in this article.

The time domain model Eq. (3) is also valid for $M$-variate time series $\mathbf{x}_{n}=$ $\left[x_{1, n}, \ldots, x_{M, n}\right]^{\prime} ;$ in this general case, the matrix AR coefficients

$\boldsymbol{\Phi}_{j}=\left[\begin{array}{cccc}\varphi_{11}^{(j)} & \varphi_{12}^{(j)} & \ldots & \varphi_{1 M}^{(j)} \\ \varphi_{21}^{(j)} & \varphi_{22}^{(j)} & \ldots & \varphi_{2 M}^{(j)} \\ \vdots & \vdots & & \vdots \\ \varphi_{M 1}^{(j)} & \varphi_{M 2}^{(j)} & \ldots & \varphi_{M M}^{(j)}\end{array}\right]$

The innovations sequence of an $M$-variate time series is $\mathbf{a}_{n}=\left[a_{1, n}, \ldots, a_{M, n}\right]^{\prime}$ and its 10 covariance matrix takes the form

$\mathbf{R}_{\mathbf{a}}=\left[\begin{array}{cccc}R_{11} & R_{12} & \ldots & R_{1 M} \\ R_{21} & R_{22} & \ldots & R_{2 M} \\ \vdots & \vdots & & \vdots \\ R_{M 1} & R_{M 2} & \ldots & R_{M M}\end{array}\right]$.

The spectral matrix Eq. (6) changes to

$\mathbf{s}(f)=\left[\begin{array}{cccc}s_{11}(f) & s_{12}(f) & \ldots & s_{1 M}(f) \\ s_{21}(f) & s_{22}(f) & \ldots & s_{2 M}(f) \\ \vdots & \vdots & & \vdots \\ s_{M 1}(f) & s_{M 2}(f) & \ldots & s_{M M}(f)\end{array}\right]$,

with $s_{i j}(f)$ being the spectral (if $i=j$ ) and cross-spectral (if $i \neq j$ ) densities, respectively,

of the time series $x_{i, n}, i=1, \ldots, M$. The spectral matrix Eq. (10) is used to calculate

CPD

11, 4701-4728, 2015

On reconstruction of time series in climatology

V. Privalsky and
A. Gluhovsky

Title Page

Abstract

Introduction

Conclusions

References

Tables

Figures

14

4

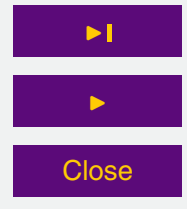

Full Screen / Esc

Printer-friendly Version

Interactive Discussion 
other spectral functions such as multiple and partial coherences, coherent spectra, etc. (see Bendat and Piersol, 2010).

The task of fitting a proper autoregressive model to a bivariate time series is discussed, for example, in Box et al. (2015), while some recommendations for the case of

5 climate data analysis can be found in Privalsky (2015). A key point in the parametric time series analysis is choosing a proper order $p$ for the model Eq. (3); the recommended approach is to do it with the help of order-selection criteria: Akaike's AIC, Schwarz-Rissanen's BIC, Parzen's CAT, and Hannan-Quinn's $\varphi$ (e.g., Parzen, 1977; Hannan and Quinn, 1979; Box et al., 2015).

\section{An example of a bivariate time series reconstruction}

The following example with actual observations - sunspot numbers and total solar irradiance of the Earth - demonstrates, among other things, that the linear regression approach to reconstructing past data is generally not correct. Specifically, it would not be proper to reconstruct past values $x_{1, n}, n=1, \ldots, N_{1}$ of any scalar time series $x_{1, n}$ 15 known over the interval $\left[N_{1}+1, N_{2}\right]$ using the linear regression between $x_{1, n}$ and another scalar time series $x_{2, n}$ known at $n=1, \ldots, N_{1}, \ldots, N_{2}$. This general statement is true as long as the modulus of the cross-correlation coefficient between $x_{1, n}$ and $x_{2, n}$ calculated for the interval $\left[N_{1}+1, N_{2}\right]$ is not equal to 1 . Note that though the dependence between time series at the input and output of any linear filter is, of course, strictly linear, the cross-correlation coefficient between them is always less than 1 .

Examples of TSI reconstruction on the basis of linear regressions can be found, for example, in Fröhlich (2009) or in Steinhilber (2009), but it should be stressed that we are discussing here mostly the method of reconstruction rather than which proxy should be used for it.

\section{CPD}

11, 4701-4728, 2015

On reconstruction of time series in climatology

V. Privalsky and A. Gluhovsky

Title Page

Abstract Introduction Conclusions References Tables Figures

\section{4} 4

Back

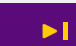

$\triangleright$

Close

Printer-friendly Version

Interactive Discussion 


\subsection{Data and data analysis}

Consider the task of restoring past values of the total solar irradiance (TSI) $x_{1, n}$ on the basis of its connection to the time series of sunspot numbers (SSN) $x_{2, n}$. The time series of monthly TSI values is available at the KNMI site http://climexp.knmi.nl/ 5 selectindex.cgi (also, see Fröhlich, 2000) while the latest set of SSN data (version 2.0) is taken from the site of the Solar Influences Data Analysis Center (see http://sidc.oma. be/). A detailed description of this new time series can be found in Clette et al. (2014). We use observation data for $x_{1, n}$ and for $x_{2, n}$ from 1979 through 2014 and from 1749 through 2014, respectively, at the sampling rate $\Delta t=1$ month $\left(N_{1}=2760, N_{2}=3192\right)$.

10 The values of TSI and SSN over the 432-month long common interval of observations from $N_{1}+1$ through $N_{2}$ are shown in Fig. 1 .

Both processes are dominated by the 11 year cycle but also show variability at smaller time scales. The autoregressive estimates of the TSI and SSN spectra are shown in Fig. 2. The optimal AR orders for the scalar time series models are $p=32$ 15 and $p=33$, respectively. The spectra contain strong peaks at the frequency $f_{\mathrm{s}} \approx$ 0.091 year $^{-1}$ and a few peaks at higher frequencies where the spectral density values are orders of magnitude lower than at $f_{\mathrm{s}}$.

Consider first the traditional approach: using the linear regression Eq. (1) to reconstruct the time series of TSI. The equation connecting TSI with SSN (in deviations from respective mean values) is

$x_{1, n} \approx 0.0043 x_{2, n}+a_{n}$,

where $a_{n}$ is the regression error.

If $x_{1, n}(\mathrm{TSI})$ and $x_{2, n}$ (SSN) were random variables, the cross-correlation coefficient $r_{12} \equiv r_{12}(0)$ between them would explain $100 \times r_{12}^{2} \%$ of the TSI variance $\sigma_{1}^{2}$. (Here $r_{12}(k)$ is the cross-correlation function between $x_{1, n}$ and $x_{2, n}$ at the lag $k$.) Indeed, the crosscorrelation coefficient between monthly values of TSI and SSN is high: $r_{12} \approx 0.77$ so that the reconstruction of TSI through the linear regression Eq. (11) would leave $100 \times$

\section{CPD}

$11,4701-4728,2015$

On reconstruction of time series in climatology

V. Privalsky and A. Gluhovsky

Title Page

Abstract

Conclusions References

Tables

Figures

14

4

Back

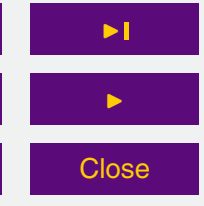

Full Screen / Esc

Printer-friendly Version

Interactive Discussion 
$\left(1-r_{12}^{2}\right) \approx 41 \%$ of the TSI variance unexplained. It is also seen from Fig. 3 that the cross-correlation $r_{12}(k)$ between $x_{1, n}$ and $x_{2, n}$ is also high at other values of lag $k$, both positive and negative, and it can even exceed the cross-correlation coefficient $r_{12}(0)$. Specifically, all values of $r_{12}(k)$ at $|k|=1,2, \ldots, 6$ are higher than $r_{12}(0)$. Obviously, the

5 regression-based approach can hardly be justified in this case because it would be rather difficult, to say the least, to construct a multiple linear regression equation for this case with such a complicated cross-correlation function.

As both SSN and TSI present time series rather than random variables, the values of TSI for the time interval from 1749 through 1978 should be reconstructed by using 10 a bivariate stochastic model Eq. (3) built on the basis of simultaneous observations of SSN and TSI from 1979 through 2014. However, before continuing with this time series analysis, the following remarks about the traditional approach are suitable here.

In studies dedicated to reconstruction of climate and to teleconnections in the Earth system, the statistical reliability of estimated cross-correlation coefficients seems to be determined without taking into accounts three important factors:

- the variance of cross-correlation coefficient estimates depends upon the behavior of the entire correlation and cross-correlation functions of the time series (see Bendat and Piersol, 2010; Box et al., 2015); besides, the maximum absolute value of the cross-correlation function does not necessarily occur at zero lag between the time series (e.g., Fig. 3) and even if it does, one cannot ignore high crosscorrelations at other lags;

- if several cross-correlation coefficients are estimated, the probability of obtaining a spuriously high value increases with the number of estimates; this had been proved long ago by none other than the founder of the modern probability theory (Kolmogorov, 1933); it means, in particular, that selecting "statistically significant" predictors out of a set of possible predictors on the basis of "statistically significant" cross-correlation coefficients between the predictors and the predictand(s) may lead to spurious results;

\section{CPD}

$11,4701-4728,2015$

On reconstruction of time series in climatology

V. Privalsky and A. Gluhovsky

Title Page

Abstract Introduction Conclusions References Tables Figures

14 4

Back
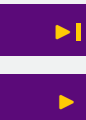

Close

Full Screen / Esc

Printer-friendly Version

Interactive Discussion 
- in the "moving interval correlation analysis" (e.g., Maxwell et al., 2015), consecutive estimates of cross-correlation coefficients are strongly dependent on each other and this makes the estimates' variance to increase.

Returning to the data analysis, the optimal time domain AR approximation for the 5 bivariate time series $\mathbf{x}_{n}=\left[x_{1, n}, x_{2, n}\right]^{\prime}, n=1, \ldots, 432$, was found to be the following $\mathrm{AR}(3)$ model selected by three of the four order selection criteria mentioned in Sect. 3:

$$
\begin{aligned}
x_{1, n} \approx & 0.32 x_{1, n-1}+0.31 x_{2, n-1}+0.11 x_{1, n-2}+0.02 x_{2, n-2} \\
& +0.07 x_{1, n-3}-0.07 x_{2, n-3}+a_{1, n} \\
x_{2, n} \approx & -0.03 x_{1, n-1}+0.57 x_{2, n-1}+0.08 x_{1, n-2}+0.14 x_{2, n-2}+0.20 x_{1, n-3} \\
& +0.13 x_{2, n-3}+a_{2, n}
\end{aligned}
$$

with the innovation covariance matrix

$\mathbf{R}_{\mathrm{a}} \approx\left[\begin{array}{cc}0.036 & -0.016 \\ -0.016 & 0.061\end{array}\right]$.

According to Eq. (13), the cross-correlation coefficient between the innovation sequences $a_{1, n}$ and $a_{2, n}$ equals -0.34 .

15 As the variances of TSI and SSN differ by several orders of magnitude, the AR coefficients in Eq. (12) and white noise variances and covariance are shown for the values of SSN divided by 100 .

The bivariate stochastic difference Eq. (12) shows that the system's memory extends for three months and that $x_{1, n}$ and $x_{2, n}$ influence each other. The eigenfrequencies of the system Eq. (12) are $f_{1}=0.25$ and $f_{2} \approx 0.11$ year $^{-1}$ with the damping coefficients $d_{1}=0.49$ and $d_{2}=0.26$. Oscillations at $f_{1}$ seem to be weak and are not seen in the spectra while the eigen-frequency $f_{2}$ is close to the frequency of oscillations at 0.091 year $^{-1}$ which dominate variations of both TSI and SSN.

The knowledge of the stochastic difference Eq. (12) and the covariance matrix 25 Eq. (13) of the innovation sequence allows one to determine the share of the TSI 4713

\section{CPD}

11, 4701-4728, 2015

On reconstruction of time series in climatology

V. Privalsky and A. Gluhovsky

Title Page

Abstract Introduction Conclusions References Tables Figures

14 4

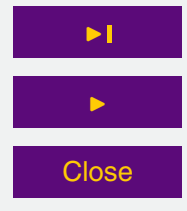

Full Screen / Esc

Printer-friendly Version

Interactive Discussion 
variance that cannot be explained with the "deterministic" components of the model Eq. (12) which describes the dependence of $x_{1, n}$ (TSI) and $x_{2, n}$ (SSN) upon their own past values and upon past values of the other scalar time series. The variance of TSI $\sigma_{1}^{2} \approx 0.170\left(\mathrm{Wm}^{-2}\right)^{2}$ while, according to Eq. (13), the variance $R_{11}$ of the innovation 5 sequence $a_{1, n}$ is $0.036\left(\mathrm{~W} \mathrm{~m}^{-2}\right)^{2}$. This means that the part of the TSI variance $\sigma_{1}^{2}$ that cannot be explained by the dependence of the time series upon the past behavior of $x_{1, n}$ and $x_{2, n}$ is $100 \times 0.036 / 0.170 \approx 21 \%$. Thus, in contrast to the linear regression case, Eq. (12) allows one to explain not about $60 \%$ but almost $80 \%$ of the TSI variance by the dependence of TSI upon its own past values and upon the past values of o sunspots numbers.

The values of the coherence function between SSN and TSI, which has been obtained from the spectral matrix corresponding to Eqs. (12) and (13), are very high (above 0.9) at frequencies below 0.14 year $^{-1}$ (Fig. 4). This means that the linear dependence between TSI and SSN at those frequencies is responsible for at least $80 \%$ 15 of time series' variances. At frequencies above 0.28 year $^{-1}$, the coherence stays below 0.7 but this weaker dependence is less important as the spectral density values there are much smaller than at the low-frequency band (Fig. 2).

\subsection{Reconstruction}

A seemingly obvious way to obtain past monthly values of TSI back to January 1749 20 would be to simulate TSI in accordance with Eq. (12), starting from December 1978 and substituting the observed SSN values at each step into the past. To start this recursive process, one will also need three (in accordance with the order $p$ of the AR model) first monthly values of TSI and SSN in 1979. However, this approach to reconstruction would be wrong because it depicts values of TSI as a function of future values of both 25 TSI and SSN:

$x_{1, n}=\varphi_{11}^{(1)} x_{1, n+1}+\varphi_{12}^{(1)} x_{2, n+1}+\ldots+\varphi_{11}^{(3)} x_{1, n+3}+\varphi_{12}^{(3)} x_{2, n+3}$.

\section{CPD}

$11,4701-4728,2015$

On reconstruction of time series in climatology

V. Privalsky and A. Gluhovsky

Title Page

Abstract

Conclusions

Tables

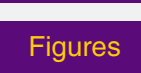

14 4

Back Introduction References Figures

\section{Full Screen / Esc}

Printer-friendly Version

Interactive Discussion 
Though the SSN data $x_{2, n}$ is known, the dependence of $x_{1, n}$ upon its unknown future values makes the linear operator Eq. (14) physically unrealizable. If, nevertheless, past values of TSI are simulated in accordance with Eq. (14), its properties in the frequency domain will be the same as before but the AR coefficients would be different from those 5 in Eq. (12).

Therefore, the past values of TSI should be reconstructed starting from the earliest observation date of SSN, that is, from January 1749. It means using the first of the Eq. (12) to reconstruct the past values of $x_{1, n}$ on the basis of its past values and the known past values of $x_{2, n}$ :

$x_{1, n} \approx 0.32 x_{1, n-1}+0.31 x_{2, n-1}+0.11 x_{1, n-2}+0.02 x_{2, n-2}+0.07 x_{1, n-3}-0.07 x_{2, n-3}$,

where $n=1, \ldots, N_{1}$. The first three values of TSI for 1749 will not include the dependence of TSI upon its past values. The unknown past values of the innovation sequence $a_{1, n}$ are not included into the reconstructed TSI time series shown in Fig. 5.

The differences between the estimates of the mean values and between the 15 variance estimates for the observed (1979-2014, $\left.N_{2}-N_{1}=432\right)$ and reconstructed (April 1749-December 1978, $N_{1}-3=2757$ ) TSI time series lie within respective confidence intervals for the estimates at a confidence level 0.90 . The confidence intervals were calculated with account for the behavior of respective correlation functions (see Yaglom, 1986). The SSN variance estimates for 1749-1978 and 1979-2014 20 were 4468 number $^{2}$ and 5471 number $^{2}$, respectively. This drop in the SSN variance in the past and the lack of the innovation sequence $a_{1, n}$ in Eq. (15) explain the decrease in the TSI variance from $0.170\left(\mathrm{~W} \mathrm{~m}^{-2}\right)^{2}$ for the observed data in 1979-2014 to $0.107\left(\mathrm{Wm}^{-2}\right)^{2}$ for the restored time series in $1749-1978$. The probability distribution functions of the observed and restored time series significantly differ from the Gaussian, which should have been expected due to the presence of the 11 year cycle.

As seen from Fig. 6, the agreement between the spectra of observed (1979-2014) and restored TSI data (1749-1978) is quite satisfactory. Note that though the crosscorrelation coefficient between SSN and the reconstructed TSI is less than 1, the co-

\section{5}

\section{CPD}

$11,4701-4728,2015$

On reconstruction of time series in climatology

V. Privalsky and A. Gluhovsky

\section{Title Page}

Abstract Introduction Conclusions References Tables Figures

\section{4}

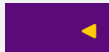

$\triangleleft$

Back

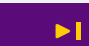

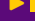

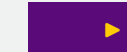

Close

Full Screen / Esc

Printer-friendly Version

Interactive Discussion 
herence between them (not shown) equals 1 at all frequencies because, according to Eq. (15), TSI is a linear function of SSN. The spectrum of the time series restored through the regression Eq. (11) stays below the spectrum of the TSI time series reconstructed through Eq. (15) at all frequencies up to 0.5 year $^{-1}$, which illustrates the 5 relative incapability of the correlation/regression approach.

To further estimate these differences in reconstructions, consider the results obtained for the interval from 1979 through 2014 over which the values of TSI are known from observations. First, according to Eq. (11), the variance of the TSI time series reconstructed through linear regression is $\varphi^{2} \sigma_{2}^{2} \approx 0.101\left(\mathrm{Wm}^{-2}\right)^{2}$ while the variance of the 10 observed TSI time series is $0.170\left(\mathrm{Wm}^{-2}\right)^{2}$. The variance of the TSI time series restored through Eq. (15) is $0.131\left(\mathrm{Wm}^{-2}\right)^{2}$. In other words, the AR approach allows one to reconstruct a substantially larger share of the process (actually, by about $22 \%$ ). If the reconstruction error is defined as the difference between the observed and reconstructed time series of TSI, the variance of the error time series will be 0.069 and $150.058\left(\mathrm{~W} \mathrm{~m}^{-2}\right)^{2}$ for the time series reconstructed on the basis of Eqs. (11) and (15), respectively.

Comparing the spectral density of the observed TSI with those of the two reconstructed time series (shown in Fig. 7 for the lower frequency band where the spectral energy is high), one can see that

- the TSI spectrum obtained through regression is mostly negatively biased with respect to the spectrum of TSI obtained through Eq. (15) and

- this spectrum (which, according to Eq. (11), is identical to the SSN spectrum up to a multiplier) differs from the spectrum of the observed TSI.

In this case, the discrepancy between the two spectra is not large because of the dominance of the 11 year solar cycle which is reproduced with both methods. But the linear regression approach cannot be justified mathematically and a $20 \%$ improvement over the traditional method cannot be ignored.

\section{CPD}

$11,4701-4728,2015$

On reconstruction of time series in climatology

V. Privalsky and A. Gluhovsky

\section{Title Page}

Abstract Introduction Conclusions References Tables Figures

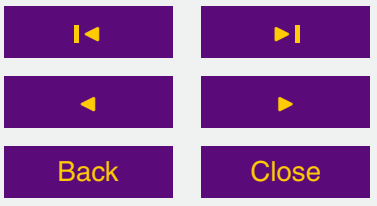
Full Screen / Esc

Printer-friendly Version

Interactive Discussion 
A more spectacular results would be obtained if one were to restore the contribution of El Niño - Southern Oscillation (ENSO) to, say, the global surface temperature (GST), or the Atlantic Multidecadal Oscillation (AMO). In those cases, the correlation coefficient between GST and ENSO or between AMO and ENSO would be very close to zero 5 ( -0.06 between AMO and the sea surface temperature in the ENSO area 3.4) while the coherence function estimates will significantly differ from zero in the frequency band between approximately 0.15 and 0.40 year $^{-1}$. In this latter case, the linear-regression contribution of ENSO to GST will be less than $0.4 \%$ while the proper autoregressive approach will show a contribution of 25 to more than $50 \%$ of spectral energy within 10 the respective frequency band (see Privalsky, 2015). In the case of GST and ENSO, the linear regression contribution is less than $10 \%$ while the autoregressive approach gives from 25 to $66 \%$ between approximately 0.1 and 0.4 year $^{-1}$.

\section{Conclusions}

The main goal of this study was to show that the task of reconstructing past values of 15 a bi-variate time series on the basis of simultaneous observations of its components during a relatively short time interval should be treated within the framework of time series analysis. This is done in the following manner:

a. build and analyze an autoregressive model of the bivaraite time series in the time and frequency domains,

b. use the model to simulate the missing time series component into the past starting from the earliest observation of the proxy data and substituting the known proxy data at each step into the difference equation for the unknown time series,

c. verify that basic statistical properties of the reconstructed component do not differ much from the properties known from observations.

\section{CPD}

11, 4701-4728, 2015

On reconstruction of time series in climatology

V. Privalsky and

A. Gluhovsky

Title Page

Abstract

Conclusions References

Tables

Figures

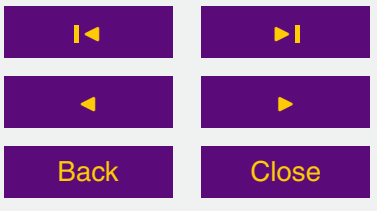

Full Screen / Esc

Printer-friendly Version

Interactive Discussion 
Note that the method does not require any filtering of the time series, be it a prewhitening or any other type of linear filters.

This approach based upon time series analysis and upon previous research in paleoclimatology was applied here to the time series containing monthly values of the total 5 solar irradiance of the Earth (TSI) measured during the interval from 1979 through 2014 and the sunspot numbers observed from 1749 through 2014 to produce an estimate of monthly TSI values from 1749 through 1978.

On the whole, it can be said that the statistical properties of the reconstructed TSI data such as its variance and spectral density do not disagree with respective proper10 ties of the observed TSI and that the time series approach produced better results than the regression-based reconstruction.

This approach to reconstruction is recommended for all cases when the spectra of the time series components differ from a constant (white noise) and/or from each other and when the cross-correlation function between the components contains more than 15 just one statistically significant value.

It must be also stressed that the autoregressive model introduced here emerges as a natural extension of the linear regression equation for the case of multivariate random functions. In particular, it means that the use of the moving average (MA) or mixed autoregressive - moving average (ARMA) models would be illogical in such cases.

20 Acknowledgements. The authors are grateful to F. Clette for providing the sunspot time series and commenting on it and to J. Guiot for his important comments and suggestions. A. Gluhovsky acknowledges support from the National Science Foundation under Grant no. AGS-1050588.

\section{References}

25 Bendat, J. and Piersol, A.: Measurement and Analysis of Random Data, Wiley, New York, 1966. Bendat, J. and Piersol, A.: Random Data, Analysis and Measurements Procedures, 4th Edn., Wiley, Hoboken, 2010.

\section{CPD}

11, 4701-4728, 2015

On reconstruction of time series in climatology

V. Privalsky and A. Gluhovsky

Title Page

Abstract Introduction Conclusions References Tables Figures

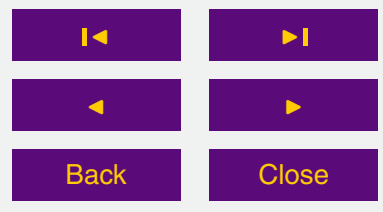

Full Screen / Esc

Printer-friendly Version

Interactive Discussion 
Box, G. and Jenkins, J.: Time Series Analysis, Forecasting and Control, Holden-Day, San Francisco, 1970.

Box, G. E. P., Jenkins, G. M., Reinsel, G. C., and Ljung, G. M.: Time Series Analysis: Forecasting and Control, 5th Edn., Wiley, London, 2015.

5 Bradley, R. S.: Paleoclimatology: Reconstructing Climates of the Quaternary, 3rd Edn., Elsevier, Boston, 2015.

Choi, B. and Cover, T.: An information-theoretic proof of Burg's maximum entropy spectrum, P. IEEE, 72, 1094-1096, 1984.

Clette, F., Svalgaard, L., Vaquero, J., and Cliver, E.: Revisiting the sunspot number, a 400-year perspective on the solar cycle, Space Sci. Rev., 186, 35-103, 2014.

Davis, B. A. S., Brewer, S., Stevenson, A. C., Guiot, J., and Data Contributors: The temperature of Europe during the Holocene reconstructed from pollen data, Quaternary Sci. Rev., 22, 1701-1716, 2003.

Douglass, A. E.: Weather cycles in the growth of big trees, Mon. Weather Rev., 37, 225-237, 1909.

Douglass, A. E.: A method of estimating rainfall by the growth of trees, in: The Climatic Factor, edited by: Huntington, E., Carnegie Inst. Wash. Publ., Washington, 101-122, 1914.

Douglass, A. E.: Climatic Cycles and Tree-Growth: a Study of the Annual Rings of Trees in Relation to Climate and Solar Activity, Carnegie Inst. Wash. Publ., 289, Vol. 1, Washington, $20 \quad 1-127,1919$.

Douglass, A. E.: Climatic Cycles and Tree-Growth: a Study of the Annual Rings of Trees in Relation to Climate and Solar Activity, Carnegie Inst. Wash. Publ., 289, Vol. 2, Washington, 1-166, 1928.

Douglass, A. E.: Climatic Cycles and Tree-Growth: a Study of Cycles, Carnegie Inst. Wash. Publ., 289, Vol. 3, Washington, 1-171, 1936.

Emery, W. and Thomson, R.: Data Analysis Methods in Physical Oceanography, 2nd Edn., Elsevier, Amsterdam, 2004.

Fritts, H. C.: Tree Rings and Climate, Academic Press, London, 1976.

Fröhlich, C.: Observations of irradiance variations, Space Sci. Rev., 94, 15-24, 2000.

30 Fröhlich, C.: Evidence of a long-term trend in total solar irradiance, Astron. Astrophys., 501, L27-L30, doi:10.1051/0004-6361/200912318, 2009.

CPD

$11,4701-4728,2015$

On reconstruction of time series in climatology

V. Privalsky and
A. Gluhovsky

Title Page

Abstract

Introduction

Conclusions References

Tables

Figures

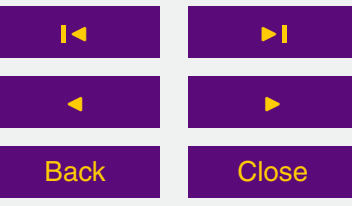

Full Screen / Esc

Printer-friendly Version

Interactive Discussion 
Gelfand, I. and Yaglom, A.: Calculation of the amount of information about a random function contained in another such function, Uspekhi Matematicheskikh Nauk, 12, 3-52, 1957, English translation: American Mathematical Society Translation Series, 2, 199-246, 1959.

Granger, C. W. J.: Investigating causal relations by econometric models and crossspectral methods, Econometrica, 37, 424-438, 1969.

Granger, C. W. J. and Hatanaka, M.: Spectral Analysis of Economic Time Series, Princeton University Press, Princeton, New Jersey, 1964.

Guiot, J.: The extrapolation of recent climatological series with spectral canonical regression, J. Climatol., 5, 325-335, 1985.

10 Guiot, J.: ARMA techniques for modelling tree-ring response to climate and for reconstructing variations of paleoclimates, Ecol. Model., 33, 149-171, 1986.

Guiot, J., Berger, A., Munaut, A. V., and Till, C.: Some new mathematical procedures in dendroclimatology, with examples from Switzerland and Morocco, Tree-Ring Bull., 42, 33-48, 1982.

Hannan, E. and Quinn, B.: The determination of the order of an autoregression, J. R. Stat. Soc., 41, 190-195, 1979.

Haslett, J., Whiley, M., Bhattacharya, S., Salter-Townshend, M., Wilson, S. P., Allen, J. R. M., Huntley, B., and Mitchell, F. J. G.: Bayesian palaeoclimate reconstruction, J. R. Stat. Soc., 169, 395-438, 2006.

20 Kolmogorov, A. N.: On the problem of the suitability of forecasting formulas found by statistical methods, Journal of Geophysics, 3, 78-82, 1933 (in Russian), English translation in Selected Works by A. N. Kolmogorov, Vol. II. Probability Theory and Mathematical Statistics, Springer, Dordrecht, 169-175, 1992.

Maxwell, J. T., Harley, G. L., and Matheus, T. J.: Dendroclimatic reconstructions from multiple co-occurring species: a case study from an old-growth deciduous forest in Indiana, USA, Int. J. Climatol., 35, 860-870, 2015.

Parzen, E.: Multiple time series: determining the order of autoregressive approximating schemes, in: Multivariate Analysis - IV, North Holland Publishing Company, Amsterdam, 283-295, 1977.

30 Privalsky, V.: On studying relations between time series in climatology, Earth Syst. Dynam., 6, 389-397, doi:10.5194/esd-6-389-2015, 2015.

Privalsky, V., Protsenko, I., and Fogel, G.: The sampling variability of autoregressive spectral estimates for two-variate hydrometeorological processes, in: Proc. 1st World Congress of the
CPD

11, 4701-4728, 2015

On reconstruction of time series in climatology

V. Privalsky and A. Gluhovsky

Title Page

Abstract Introduction

Conclusions References

Tables Figures

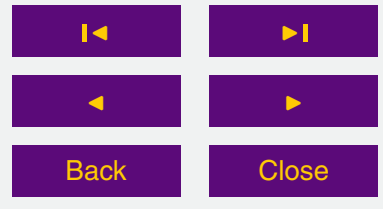

Full Screen / Esc

Printer-friendly Version

Interactive Discussion 
Bernoulli Society on Mathematical Stat. Theory and Applications, 8-14 September, 1986, Tashkent, Vol. 2, VNU Science Press, Utrecht, 651-654, 1987.

Robinson, E.: Multichannel Time Series Analysis with Digital Computer Programs, Holden-Day, San Francisco, 1967.

5 Robinson, E. and Treitel, S.: Geophysical Signal Analysis, Prentice-Hall, Englewood Cliffs, NJ, 1980.

Santos, J. A., Carneiro, M. F., Correia, A., Alcoforado, M. J., Zorita, E., and GómezNavarro, J. J.: New insights into the reconstructed temperature in Portugal over the last 400 years, Clim. Past, 11, 825-834, doi:10.5194/cp-11-825-2015, 2015.

10 Steinhilber, F., Beer, J., and Fröhlich, C.: Total solar irradiance during the Holocene, Geophys. Res. Lett., 36, L19704, doi:10.1029/2009GL040142, 2009.

Tingley, M. P. and Huybers, P.: A Bayesian algorithm for reconstructing climate anomalies in space and time, Part I: development and applications to paleoclimate reconstruction problems, J. Climate, 23, 2759-2781, 2010.

Tingley, M. P., Craigmile, P. F., Haran, M., Li, B., Mannshardt, E., and Bala Rajaratnam, B.: Piecing together the past: statistical insights into paleoclimatic reconstructions, Quaternary Sci. Rev., 35, 1-22, 2012.

Visser, $\mathrm{H}$. and Molenaar, J.: Kalman filter analysis in dendroclimatology, Biometrics, 44, 929940, 1988.

20 von Storch, H., Zorita, E., Jones, J. M., Dimitriev, Y., Gonzalez-Rouco, F., and Tett, S. F. B: Reconstructing past climate from noisy data, Science, 306, 679-682, 2004.

Yaglom, A. M.: Correlation Theory of Stationary and Related Functions, Springer, New York, 1986.

\section{CPD}

11, 4701-4728, 2015

On reconstruction of time series in climatology

V. Privalsky and
A. Gluhovsky

Title Page

Abstract

Introduction

Conclusions

References

Tables

Figures

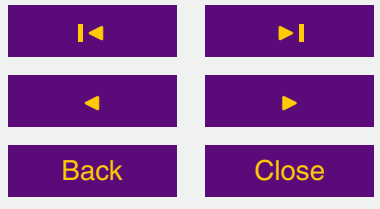

Full Screen / Esc

Printer-friendly Version

Interactive Discussion 


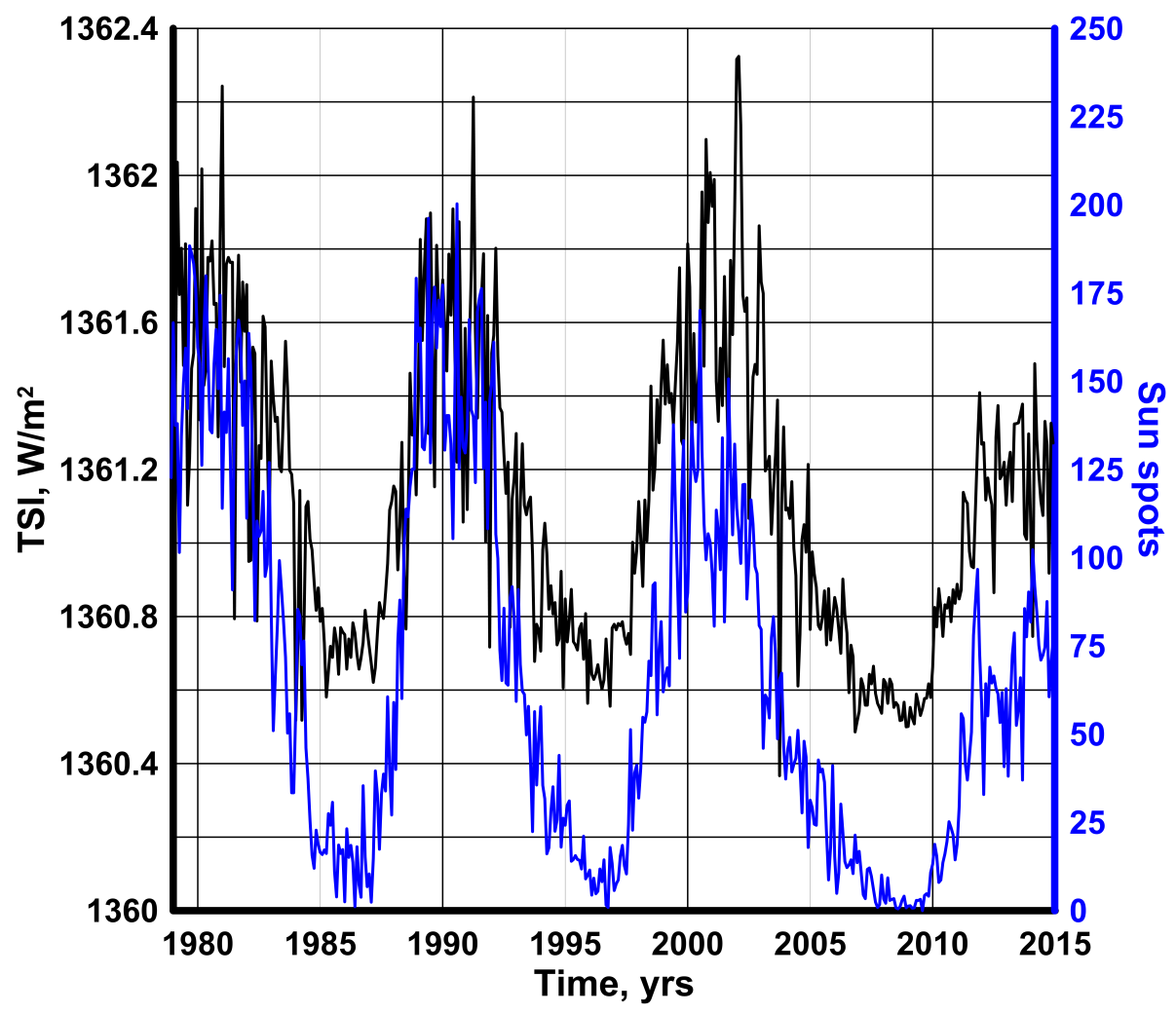

CPD

11, 4701-4728, 2015

On reconstruction of time series in climatology

V. Privalsky and
A. Gluhovsky

Title Page
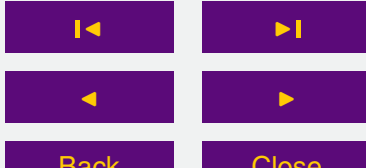

Back

Full Screen / Esc

Figure 1. Observed monthly values of TSI (black) and SSN (blue), 1979-2014.

Printer-friendly Version

Interactive Discussion 


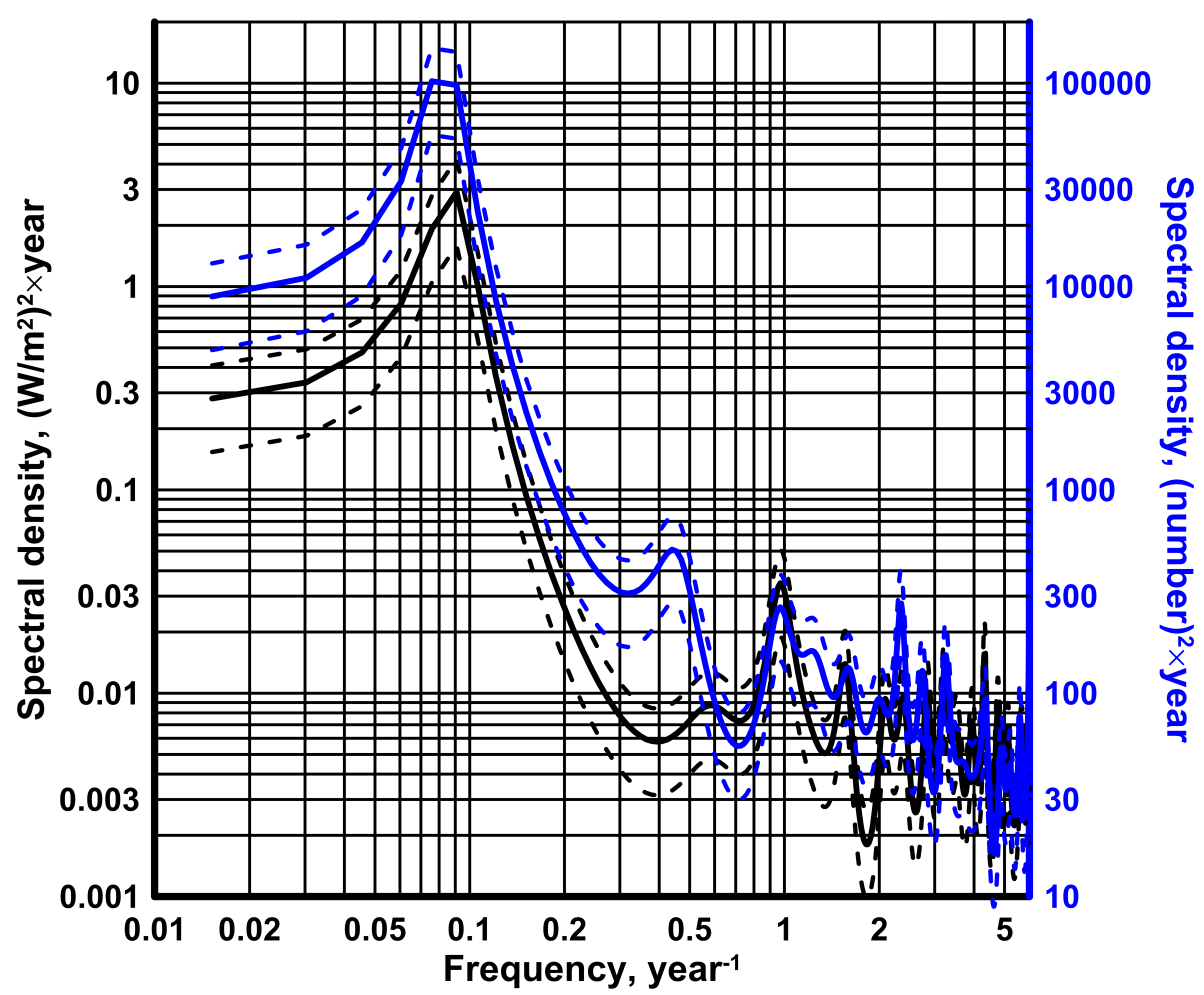

Figure 2. Autoregressive spectral estimates of monthly TSI (black) and SSN (blue) with approximate $90 \%$ confidence bands (dashed lines), 1979-2014.
CPD

$11,4701-4728,2015$

On reconstruction of time series in climatology

V. Privalsky and
A. Gluhovsky

Title Page

Abstract

Introduction

Conclusions

References

Tables

Figures

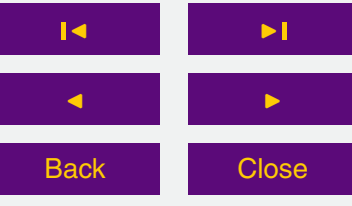

Full Screen / Esc

Printer-friendly Version

Interactive Discussion

(c) (i) 


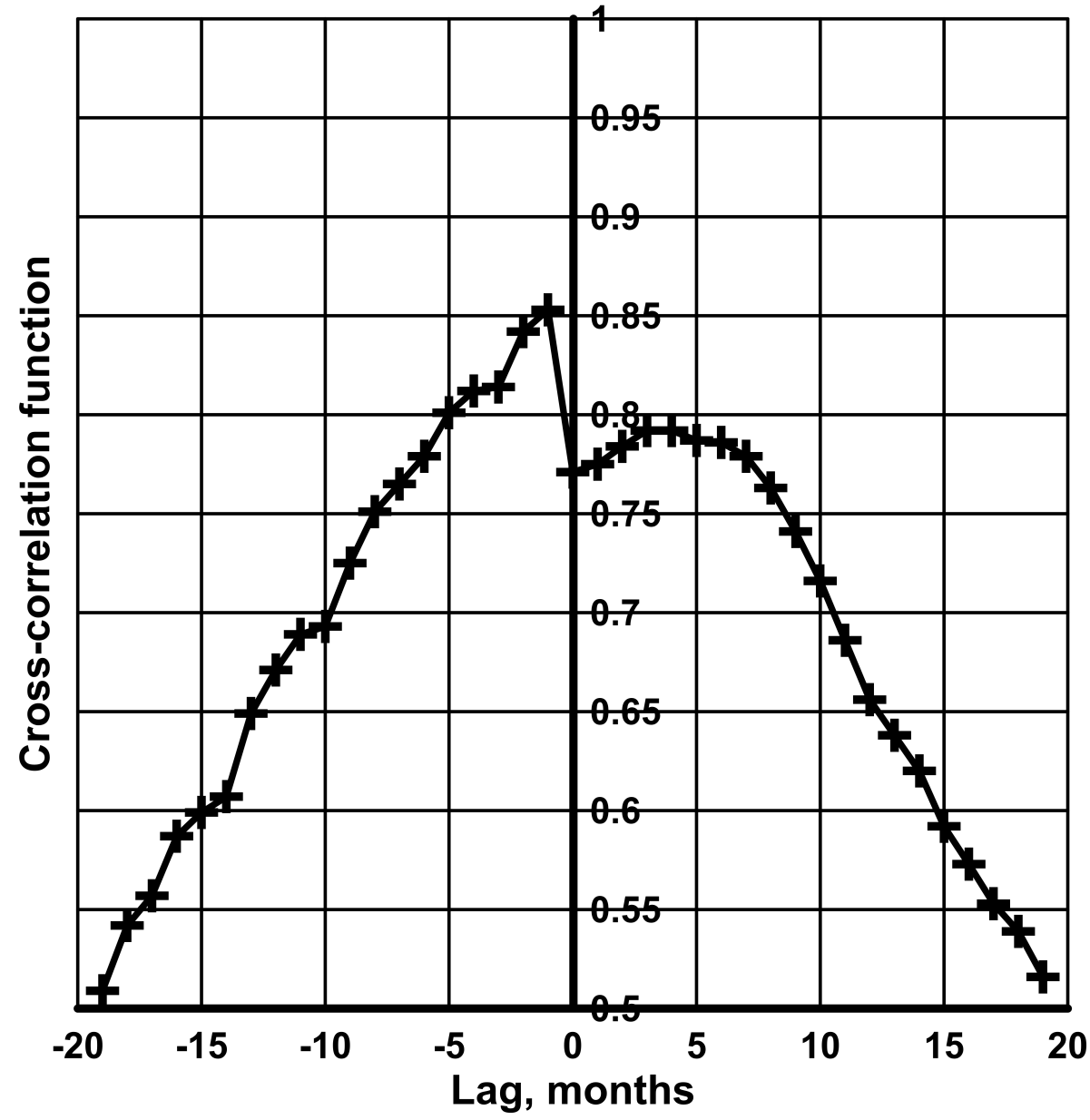

Figure 3. Estimated cross-correlation function between TSI and SSN, 1979-2014.

\section{CPD}

11, 4701-4728, 2015

On reconstruction of time series in climatology

V. Privalsky and
A. Gluhovsky

\section{Title Page}

14

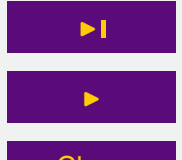

\section{Back}

Close

\section{Full Screen / Esc}

Printer-friendly Version

Interactive Discussion

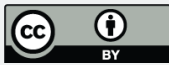




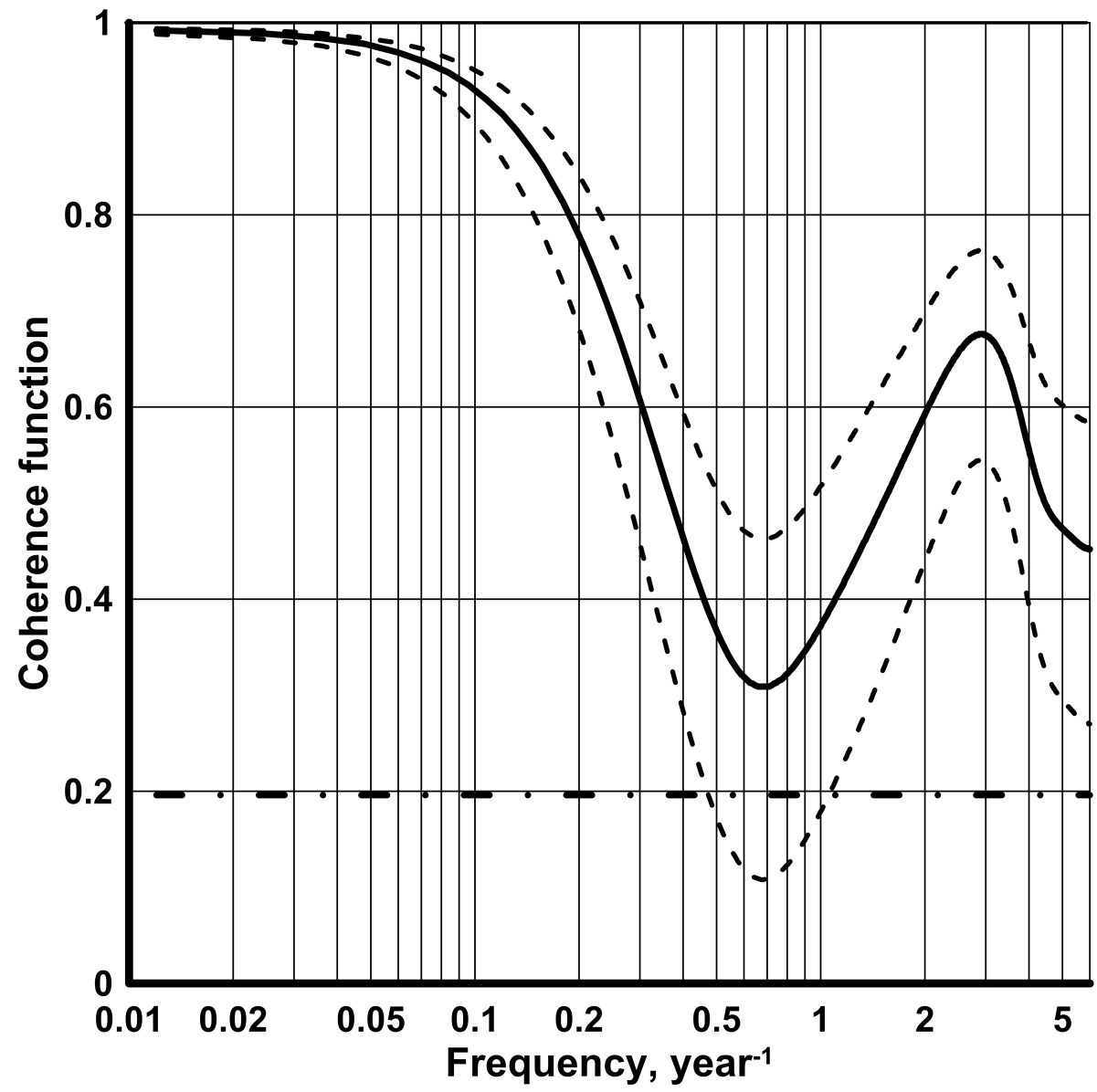

Figure 4. Estimated coherence function TSI-SSN, 1979-2014, with approximate $90 \%$ confidence band (dashed lines, see Privalsky et al., 1987, 2015). The horizontal line is the approximate $90 \%$ upper limit for the true zero coherence estimate.

\section{CPD}

11, 4701-4728, 2015

On reconstruction of time series in climatology

V. Privalsky and
A. Gluhovsky

\section{Title Page}
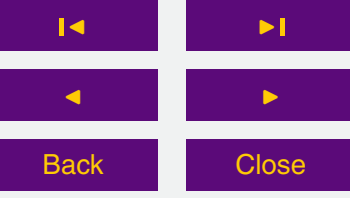

Full Screen / Esc

Printer-friendly Version

Interactive Discussion 


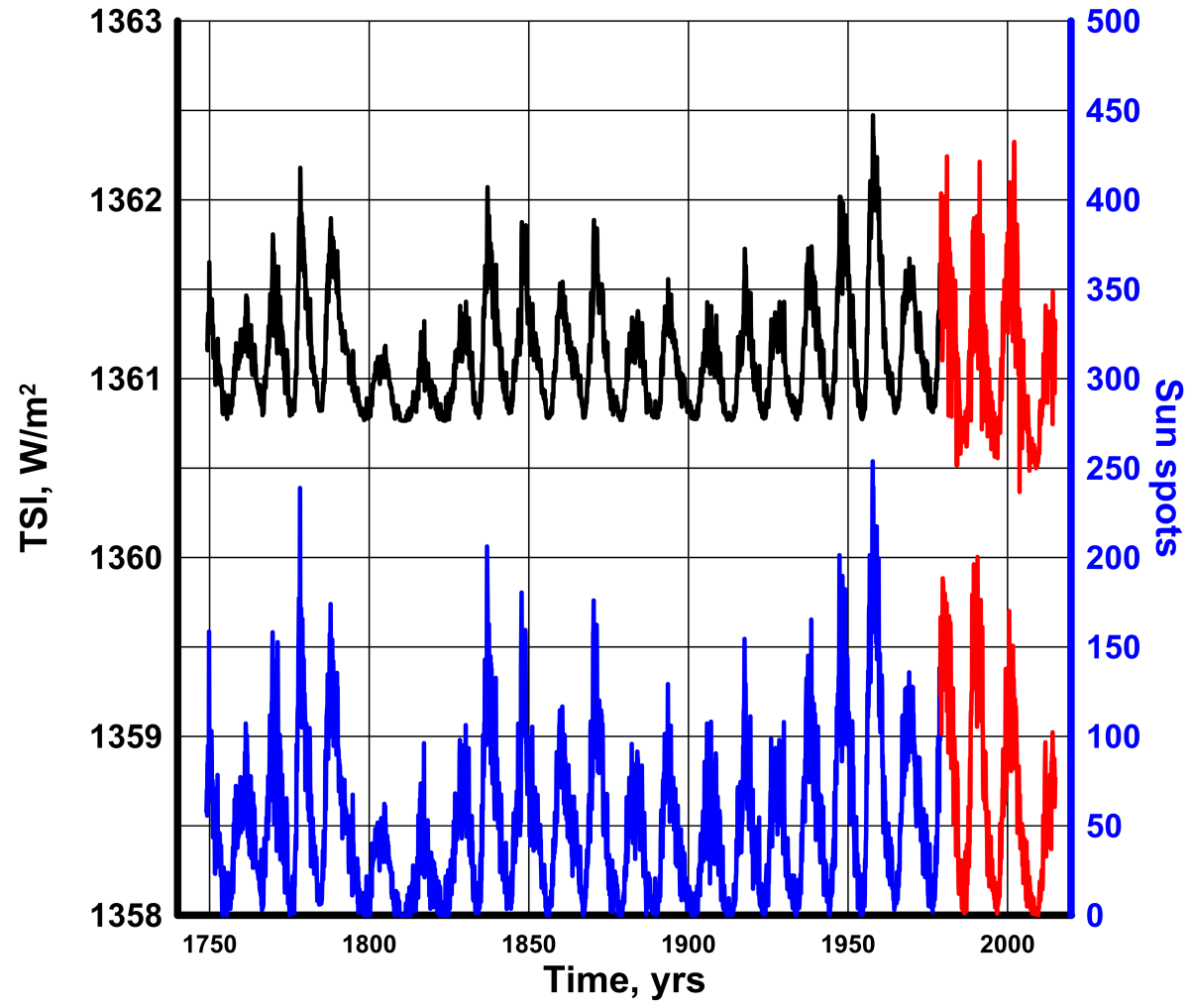

Figure 5. Restored (black) and observed (blue) monthly values of TSI and SSN, 1749-1978. The red lines show the observed TSI and SSN, 1979-2014.

\section{CPD}

11, 4701-4728, 2015

On reconstruction of time series in climatology

V. Privalsky and
A. Gluhovsky

Title Page
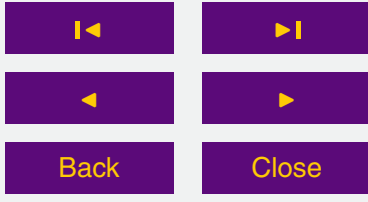

Full Screen / Esc

Printer-friendly Version

Interactive Discussion 


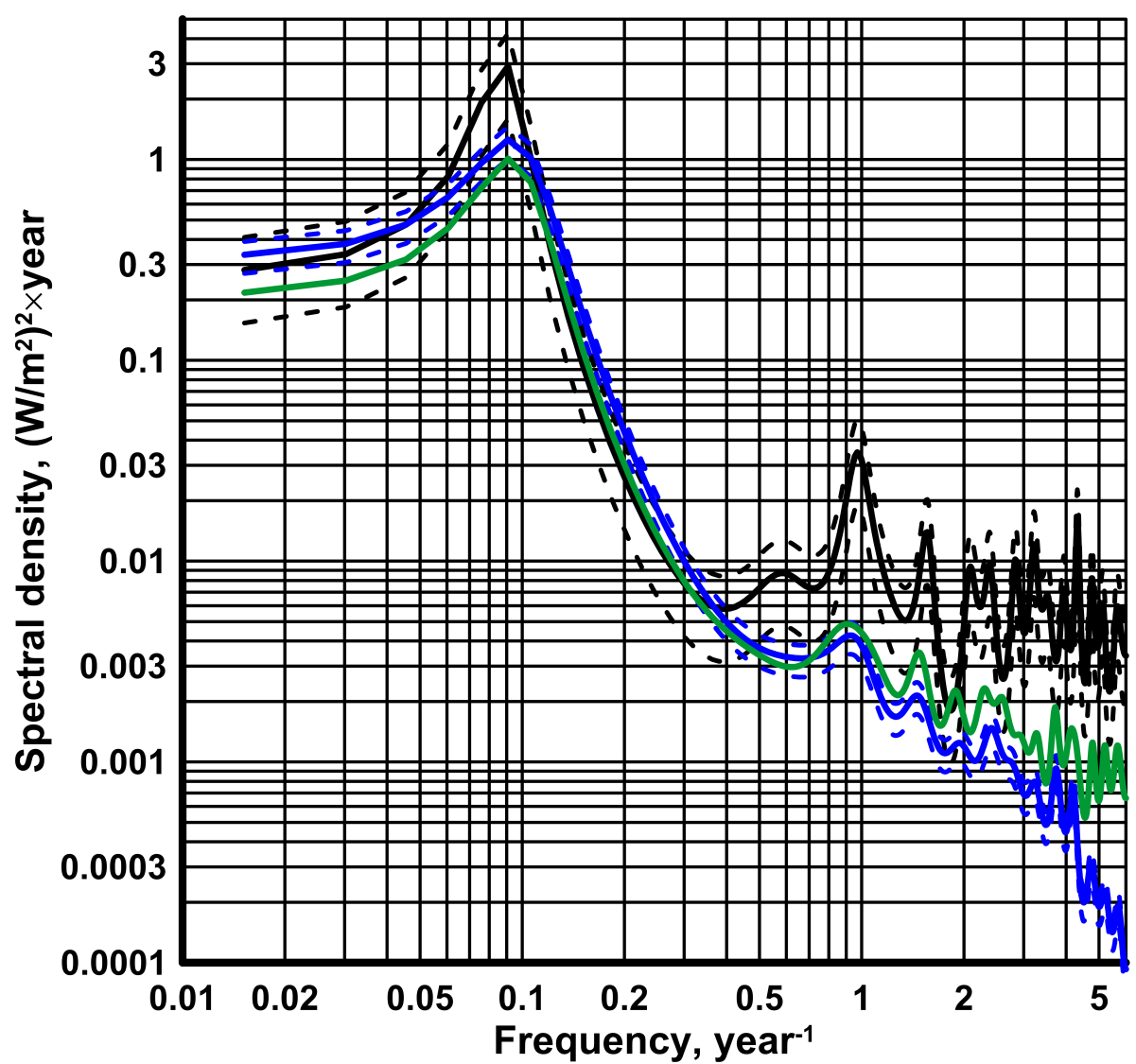

Figure 6. AR spectra of monthly observed and reconstructed TSI data for 1749-1978 (black and blue lines, respectively) with approximate $90 \%$ confidence bands (dashed lines). The spectrum of TSI reconstructed through the regression Eq. (12) is shown with the green line.
CPD

$11,4701-4728,2015$

On reconstruction of time series in climatology

V. Privalsky and
A. Gluhovsky

\section{Title Page}

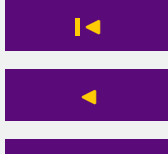

$>1$

Back

Close

Full Screen / Esc

Printer-friendly Version

Interactive Discussion 


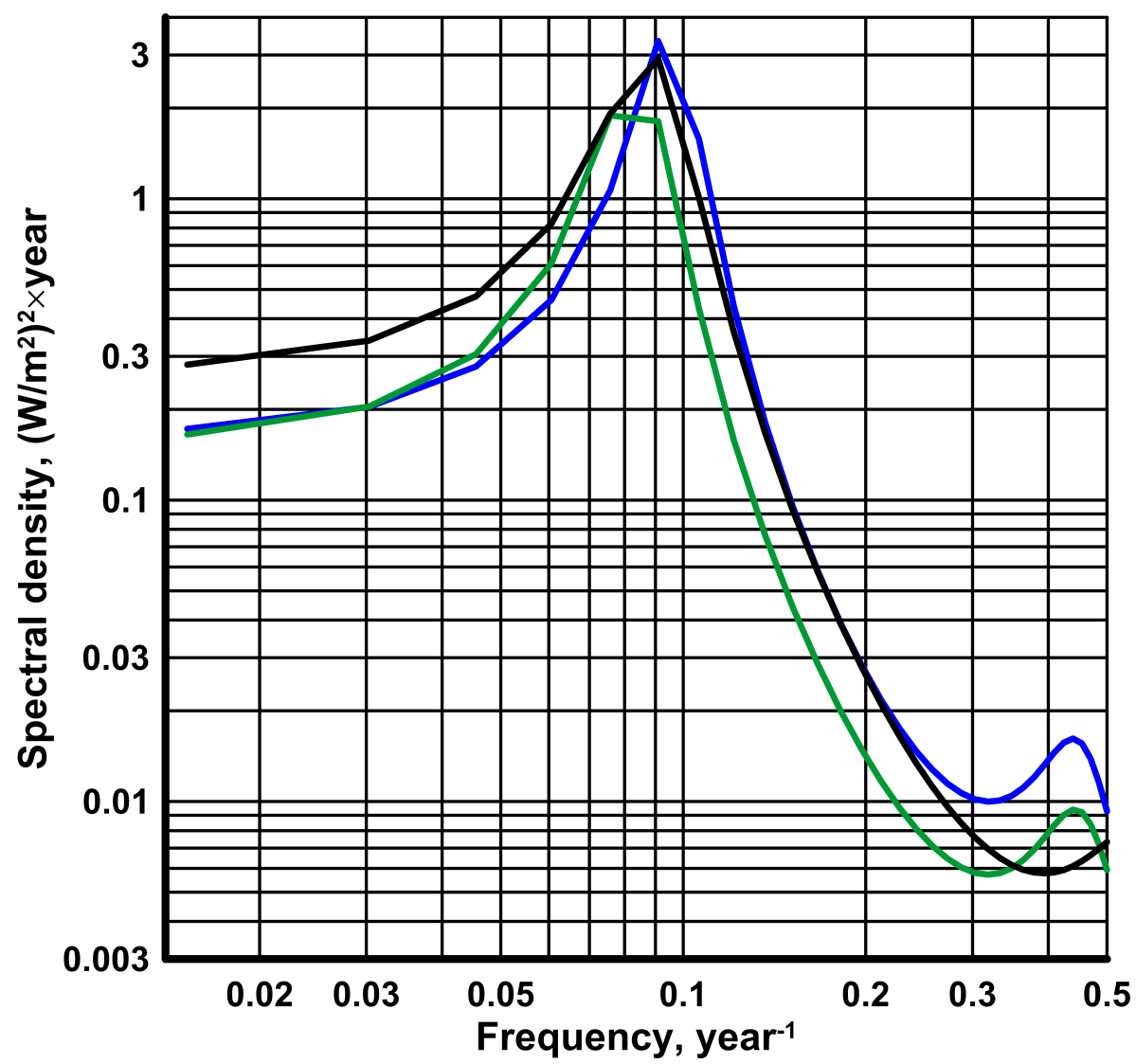

Figure 7. AR spectra of observed (1979-2014, black line) and reconstructed (1749-1978, blue and green lines) time series of TSI. The spectrum of TSI reconstructed through the regression Eq. (12) is shown with the green line.
CPD

11, 4701-4728, 2015

On reconstruction of time series in climatology

V. Privalsky and
A. Gluhovsky

\section{Title Page}
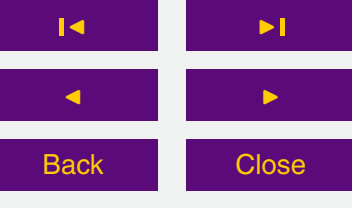

Full Screen / Esc

Printer-friendly Version

Interactive Discussion 